Didáctica. Lengua y literatura

ISSN: 1130-0531

http://dx.doi.org/10.5209/DIDA.61952

\title{
Enseñar y aprender la coherencia textual: una propuesta didáctica a partir de la teoría de Michel Charolles
}

\author{
Alejandra Andueza Correa ${ }^{1}$; Natalia Aguilera Meneses ${ }^{2}$
}

Recibido: 12 de diciembre de 2017 / Aceptado: 2 de julio de 2018

Resumen. Uno de los aspectos críticos del aprendizaje de la escritura es el dominio de la coherencia textual que, siguiendo a Charolles, es el principio mediante el cual interpretamos el discurso y la condición fundamental para que los textos logren su propósito comunicativo. A pesar de su importancia, la coherencia es raramente enseñada de manera explícita y sistemática en la escuela lo cual puede explicar, al menos en parte, los bajos resultados que obtienen los estudiantes en esta área. En vista de lo anterior, este artículo conceptualiza la coherencia a partir del trabajo de Charolles y sus colaboradores, y plantea una propuesta didáctica de tres fases a lo largo de las cuales los estudiantes adquieren conocimientos sobre coherencia y lo aplican en el proceso de producción textual mediante estrategias didácticas que promueven la autorregulación y el monitoreo durante las etapas de planificación, textualización y revisión de textos.

Palabras clave: Coherencia textual; mecanismos de estructuración del discurso; enseñanza de la escritura; proceso de producción textual; estrategias de autorregulación y monitoreo.

\section{[en] Teaching and Learning Textual Coherence: A Didactic Proposal Based on the Theory of Michel Charolles}

\begin{abstract}
One critical aspects of learning to write is to achieve textual coherence, which according to Charolles, is a general principle in the interpretation of discourse and a fundamental condition for texts to fulfill their communicative purpose. However, in spite of its importance, coherence is rarely explicitly and systematically taught in school, which explains, at least to some extent, students' low performance in that domain. In view of the above, this article conceptualizes coherence from the work of Charolles and his collaborators; and offers a didactic proposal consisting of three phases along which students become familiar with the concept of coherence and are able to apply that knowledge to the writing process, by means of strategies that promote self-regulation and monitoring during planning, writing and revision.
\end{abstract}

Keywords: Textual Coherence; discourse structuring devices; writing instruction; writing process; self-regulation and monitoring strategies.

\footnotetext{
1 Departamento de Lengua y Literatura. Universidad Alberto Hurtado (Chile) E-mail: aandueza@uahurtado.cl

2 Departamento de Lengua y Literatura. Universidad Alberto Hurtado (Chile) E-mailinaguilera@uahurtado.cl
} 


\section{[fr] Enseigner et apprendre la cohérence textuelle: une proposition didactique à partir de la théorie de Michel Charolles}

Résumé. Un des aspects fondamental dans l'apprentissage de l'écriture est le domaine de la cohérence textuelle qui, selon Charolles, est le principe par lequel nous interprétons le discours et la condition nécessaire pour que les textes accomplissent leur fonction communicative. Malgré son importance, la cohérence est rarement matière d'enseignement explicite et systématique dans le cursus scolaire ce qui pourrait expliquer, du moins en partie, le faible taux de réussite des étudiants dans ce domaine. S'appuyant sur ce constant, cet article conceptualise la cohérence à partir des travaux de Charolles et de ses collaborateurs, proposant une série d'activités divisée en trois phases au cours desquelles les étudiants acquièrent les connaissances nécessaires et les appliquent dans un processus de production d'écrit à partir de stratégies didactiques qui développent l'autorégulation durant les étapes de planification, d'écriture et de correction des textes.

Mots-clés: Cohérence textuelle; mécanismes de structuration du discours; enseignement de l'écriture; processus de production de texte; stratégie d'autorégulation.

Sumario. 1. Introducción. 2. Marco teórico. 2.1. La coherencia como principio para la interpretación del discurso. 2.2. Construcción de sentido: mecanismos estructuradores del discurso. 2.2.1. Anáforas y conectores. 2.2.2. Adverbios de enmarcamiento. 3. Propuesta didáctica: enseñar y evaluar la coherencia en el proceso de producción textual. 3.1. Fase I: Acercamiento al fenómeno. Percepciones del lector: coherencia y comprensión lectora. 3.2. Fase II: Adquisición de conocimiento metacognitivo declarativo y procedimental: operacionalizar la coherencia mediante tres principio y aplicarlos al análisis de textos. 3.3. Fase III: Monitorear y autorregular la coherencia a lo largo del proceso de producción textual. 3.3.1. Etapa de planificación: proyectar la construcción de la coherencia. 3.3.2. Etapa de textualización: monitorear y autorregulas la construcción de la coherencia. 3.3.3. Etapa de revisión: evaluar el logro de la coherencia, identificar errores y realizar mejoras. 4. Conclusiones. 5. Referencias bibliográficas.

Cómo citar: Andueza Correa, A.; Aguilera Meneses, N. (2018) Enseñar y aprender la coherencia textual: una propuesta didáctica a partir de la teoría de Michel Charolles, Didáctica. Lengua y literatura, $30,23-40$.

\section{Introducción}

La producción de textos escritos es una herramienta clave para el desarrollo del pensamiento humano ya que, por un lado, promueve el aprendizaje y la transformación del conocimiento (Balgopal y Wallace, 2013; Bereiter y Scardamalia, 1987; Klein y Rose, 2010) y, por otro, favorece la adquisición de diversos géneros discursivos que nos permiten comunicarnos y participar en las diversas esferas de la actividad humana (Bazerman, 2012a y 2012b). Escribir textos, especialmente los pertenecientes a géneros discursivos complejos (Bajtín, 2008) supone orquestar una serie de estrategias y aplicar diversos conocimientos lingüísticos y metacognitivos que raramente se desarrollan de manera espontánea, sino que deben ser enseñados de manera explícita y sistemática.

A pesar de lo anterior, diversas mediciones realizadas en Chile indican que la enseñanza de la escritura no está siendo eficiente. En efecto, los estudiantes obtienen bajos resultados en la prueba SIMCE de escritura: los datos agregados de 2014 reportan que solo un $23,3 \%$ de los estudiantes alcanza el nivel máximo en coherencia y el $13,5 \%$ lo alcanza en cohesión.

Por su parte, las investigaciones en el ámbito escolar muestran que los estudiantes no cuentan con las habilidades necesarias para construir la coherencia textual 
como es requerido en la escritura experta. Concha y Paratore (2011) estudiaron la coherencia local en textos argumentativos escritos por estudiantes de cuarto medio y reportaron que, a pesar de que gran parte de ellos fue calificado como mayormente coherente, dicha coherencia fue lograda mediante largas secuencias de razonamiento unidas por conectores básicos, que solo tienen la capacidad de relacionar ideas adyacentes del texto, pero no de interrelacionar porciones más grandes con nuevas secciones. Lo anterior, observan las autoras, difiere, en gran medida, de los mecanismos que utilizan los escritores maduros para escribir textos expositivos.

Estos resultados son consistentes con una investigación posterior en la que Concha, Aravena, Coloma y Romero (2010) estudiaron el uso de mecanismos de coherencia local y global en tres niveles de escolaridad ${ }^{3}\left(5^{\circ}\right.$ básico y $1^{\circ}$ y $4^{\circ}$ medio $-10,14$ y 18 años respectivamente-). Los resultados indican que en el nivel escolar básico $\left(5^{\circ}\right)$ la coherencia local se logra a partir de los recursos orales que los estudiantes ya poseen (como la adyacencia o el uso del conector ' $y$ ') en lugar de recursos del lenguaje más sofisticados aprendidos en la escolaridad. En cuanto a los estudiantes de enseñanza media, estos muestran un mayor domino de recursos propios de la coherencia local, lo que impacta positivamente en la coherencia global de sus textos. Sin embargo, sus resultados siguen siendo deficientes (puntúan bajo nivel en el instrumento de medición), por lo que la construcción de la coherencia no puede considerarse una habilidad adquirida.

En un estudio de Sotomayor et al. (2013) se analizan las narraciones producidas por estudiantes de $3^{\circ}, 5^{\circ}$ y $7^{\circ}$ básico $(9,11$ y 13 años, respectivamente). Los resultados de este estudio indican que, en términos de coherencia, si bien se aprecia una mejora a lo largo de las edades -el 9\% de los estudiantes de $3^{\circ}$ básico, el $36 \%$ de los de $5^{\circ}$ y el $56 \%$ de los de $7^{\circ}$ alcanzan el mayor nivel de coherencia-, los niveles de logro siguen siendo bajos.

Adicionalmente, los diagnósticos que diversas universidades chilenas realizan a sus estudiantes de primer año coinciden en indicar que la mayoría de ellos no cuenta con las habilidades necesarias para resolver de manera exitosa las demandas de la escritura académica, dentro de las cuales se encuentra la coherencia (Bitrán, Zúñiga, Flotts, Padilla y Moreno, 2009; Cabrera, 2014; Errázuriz, Arriagada, Contreras y López, 2015).

Probablemente el bajo nivel de logro de la coherencia textual se deba, al menos en parte, a que es un fenómeno que raramente se enseña de manera explícita y sistemática en los procesos de enseñanza aprendizaje de la escritura. En vista de lo anterior, el presente trabajo tiene como objetivo presentar una propuesta didáctica de tres fases. En la primera fase, el fenómeno de la coherencia se enseña como conocimiento metacognitivo declarativo, a partir del trabajo de Charolles y sus colaboradores. En la segunda fase, se aplica este conocimiento al análisis de textos, mientras que, en la tercera fase, se proponen estrategias para monitorear y autorregular el logro de la coherencia textual, durante el proceso de escritura. En conjunto, esperamos que la propuesta didáctica permita a los estudiantes conocer, aplicar y llegar a dominar los mecanismos que permiten elaborar textos coherentes.

El sistema educativo chileno está organizado en torno a dos ciclos: básico y medio. El ciclo básico consiste en ocho niveles (de primero a octavo básico, que comprende las edades de 7 a 14 años). El ciclo medio consta en cuatro niveles, de primero a cuarto medio (cuyas edades van de los 15 a los 18 años). 


\section{Marco teórico}

\subsection{La coherencia como principio para la interpretación del discurso}

De acuerdo con Charolles (1983) la coherencia es un principio general mediante el cual interpretamos todas las acciones humanas. Según el autor, toda vez que observamos a alguien llevar a cabo una serie de acciones sucesivas, suponemos -necesariamente-, que esas acciones constituyen un todo, es decir, que están motivadas por una intención global que justifica el orden en que cada una de ellas ha sido realizada.

Según Charolles (1983, 1995 y 2011) y Charolles y Vigiers (2005) este principio de coherencia rige en la interpretación del discurso, dado que cuando un emisor transmite un mensaje a un receptor, el receptor asume de manera automática que su interlocutor tiene la intención de comunicar algo, y que ese algo es un todo coherente. Lo anterior se explica porque la emisión de todo discurso tiene como objetivo manifestar públicamente una intención, y está motivada por el deseo consciente de comunicar algo a otra persona.

En otras palabras, cada vez que percibimos un conjunto de proposiciones expresadas secuencialmente, es decir, una al lado de la otra, asumimos que constituyen un discurso e intentamos determinar a qué intención global responden. Charolles (2011) explica que el orden en que las proposiciones son expresadas juega un rol central en la interpretación de la intención del discurso, ya que el receptor busca conectar las proposiciones sucesivas en un razonamiento susceptible de explicar que un locutor diga una cosa después de la otra. Para construir este razonamiento, el receptor se apoya en conocimientos comunes sobre los estados de las cosas evocadas por los enunciados. Charolles (2011) ilustra este fenómeno a través del siguiente ejemplo, en el que un pasajero, sentado en el asiento trasero del auto, escucha estas oraciones expresadas en una secuencia: (a) Conductor: El auto está haciendo un ruido extraño. (b) Copiloto (inmediatamente después): se me quedó la billetera en casa (2011: 154).

De acuerdo con Charolles (2011), el tercer pasajero de forma inmediata intentará reconstruir la línea de pensamiento que conecta la oración (a) con la (b) dado que han sido expresadas de manera sucesiva. Para esto, el oyente podría reflexionar de la siguiente manera en un intento de dar sentido al discurso que acaba de escuchar:

- Si el auto tiene un ruido extraño, puede ser que esté averiado.

- Si está averiado, habrá que repararlo.

- Si hay que repararlo, habrá que llevarlo a un taller mecánico.

- Si hay que llevarlo a un taller mecánico, habrá que pagar una cuenta.

- Si hay que pagar una cuenta, se necesitará una billetera.

- Como el copiloto no tiene su billetera, no va a ser posible que pague.

Charolles (2011) sostiene que también es posible que el oyente se conforme con advertir que la oración (a) y (b) tienen algo en común: son estados de cosas que ocurren en el mismo instante, en el mismo lugar y que presentan una misma polaridad negativa. Ante esto, podría concluir que lo que justifica que de la oración (a) sea adyacente a la (b) es, por ejemplo, la idea: "hoy es un día nefasto". Cuando la interpretación es demasiado costosa o rebuscada, el oyente va a estar inclinado a explorar otro posible sentido, o podría, incluso, renunciar a comprender. 
Dado que el emisor normalmente desea que el receptor entienda el mensaje que quiere transmitir, la formulación del texto busca esencialmente facilitar esa tarea (Charolles, 1983). Para esto, el emisor incorpora diversos mecanismos que ayudan al receptor a comprender el sentido del texto, de modo que este haga la menor parte del trabajo. Mediante estos mecanismos el emisor establece relaciones explícitas entre las ideas del texto para que el receptor pueda vincularlas tal y como el emisor desea que lo haga. Esto facilitará que la construcción del sentido por parte del receptor sea congruente con el mensaje que el emisor pretende transmitir (Charolles, 1983 y 1997; Sarda, Carter-Thomas, Faggard y Charolles, 2014).

En este sentido, la producción del discurso supone que el emisor se sitúa a una cierta distancia de su propio punto de vista para hacer su texto accesible a otros. Así, la escritura de un texto implica el desafío de proyectar el modo en que la coherencia va a ser desarrollada y preparar el texto para que otro lo comprenda. El modo en que el emisor prepara el discurso para el beneficio de los demás, refleja cómo comprende las ideas del texto y cómo es capaz de relacionar esas ideas entre sí para formar un todo.

\subsection{Construcción de sentido: mecanismos estructuradores del discurso}

De acuerdo con Charolles, Le Draoulec, Péry-Woodley y Sarda (2005), la lengua cuenta con diversos mecanismos para la estructuración del discurso que tienen gran incidencia en la construcción de la coherencia textual: las anáforas, los conectores y los adverbios de enmarcamiento.

\subsubsection{Anáforas y conectores}

Pese a que es muy común encontrar estudios de enfoque lingüístico que tratan las referencias anafóricas y los conectores por separado, Charolles (2011) trata ambos mecanismos de estructuración del discurso de forma conjunta, dado que los conectores y las anáforas comparten una característica común: son marcas de conexión orientadas hacia los enunciados anteriores. El autor explica lo anterior mediante el siguiente ejemplo: Él es profundamente prejuicioso, pero se le perdona porque es inconsciente de serlo (adaptado de Le Parisien Libéré 14/01/05).

En este ejemplo, 'se' y 'es' son anáforas que refieren al pronombre 'Él', situado en posición anterior. Lo mismo ocurre con 'le' y '-lo', que refieren a 'ser profundamente prejuicioso', que también se encuentra en una posición anterior.

En cuanto a los conectores, 'pero' indica una oposición entre las proposiciones: 'es profundamente prejuicioso' y 'se le perdona'. Esta oposición permite realizar una corrección argumentativa, mediante la cual el lector re-interpreta la primera proposición, atenuándola. De esta forma, volvemos a comprender -retrospectivamentela primera proposición gracias al proceso interpretativo gatillado por el conector 'pero'. Algo similar ocurre con el conector 'porque', que explicita la relación de causalidad entre 'se le perdona' y 'es inconsciente de serlo'.

Las expresiones anafóricas, por un lado, contribuyen al contenido proposicional de las oraciones en las que ocurren y están sintácticamente integradas. Puesto que

Traducción y adaptación propia. 
su función es actualizar el tópico del texto, son principalmente sustantivos, frases sustantivas y pronombres átonos y tónicos, razón por la que toman muchas veces la posición de sujeto oracional o de una frase sustantiva yuxtapuesta.

Los conectores, al igual que las anáforas, establecen relaciones con los elementos anteriores del discurso. Sin embargo, a diferencia de estas, su función no consiste en asegurar la continuidad del tema, sino en relacionar los nuevos contenidos que van integrándose al texto con la información ya presente. Es decir, contribuyen a establecer la progresión semántica del texto, explicitando cómo la información nueva del texto se relaciona con el tema establecido a partir de las repeticiones vehiculadas por las anáforas. Los conectores señalan los vínculos entre los contenidos proposicionales del texto sin estar sintácticamente integrados en la oración en la que están insertos. Son partículas muchas veces invariables que establecen vínculos entre oraciones, frases o párrafos. Tienen un contenido proposicional propio (Charolles, 1997) que impacta la comprensión retrospectiva del sentido del texto.

\subsubsection{Adverbios de enmarcamiento}

De acuerdo con Charolles (2011) y Charolles y Vigier (2005), existe un conjunto de mecanismos que también intervienen en la construcción de la coherencia textual, pero que han sido mucho menos estudiados por la lingüística debido a que no están directamente relacionados con la progresión temática, sino que más bien, se relacionan con la organización global de la información. El autor denomina estos mecanismos 'adverbios de enmarcamiento' y se refieren a expresiones que crean marcos del discurso mediante los cuales se evalúan las proposiciones expresadas en él.

Para el autor, un marco del discurso es un conjunto de oraciones unidas por el hecho de que deben ser interpretadas en referencia a un criterio específico que es explicitado mediante una expresión inicial introductoria (Colonna, Charolles, Sarda y Pynte, 2014). Esta expresión inicial tiene el potencial de determinar no solo la interpretación de la proposición siguiente, sino que se proyecta a lo largo de varias proposiciones consecutivas, es decir, tiene un alcance mayor que la oración en la que está inserta. En el siguiente fragmento, podemos observar algunas características generales de estas expresiones:

En general, la gente se da la mano derecha cuando se encuentra o se separa, o bien se besa. Hello, buen día, namaste! En nuestro país (Francia), un beso es sobre todo una prueba de amor y de ternura hacia alguien querido, pero en ciertos pueblos es un saludo corriente. En India, la gente se saluda con las manos juntas sobre el pecho, como si rezaran. En Japón, la gente se inclina repetidas veces, cara a cara, juntando las manos. En Francia, los hombres besaban la mano de las mujeres casadas en señal de respeto y a las jóvenes les saludaban con una reverencia, sin embargo, esta costumbre se pierde cada día más (Charolles, 1997: 6) ${ }^{5}$.

A partir del ejemplo anterior, Charolles (1997) explica que es posible distinguir una serie de adverbios que delimitan las circunstancias con respecto a las cuales debe ser evaluada la verdad o falsedad de las proposiciones que el adverbio agrupa. De

Traducción propia. 
este modo, el adverbio de enmarcamiento 'En general' abre un universo del discurso genérico, que puede ser interpretado como 'en la mayoría de los países'. Este universo será luego restringido por los adverbios de enmarcamiento que se introducen sucesivamente: 'En nuestro país', 'En India', 'En Japón’ y 'En Francia', cuya función es indicar que la forma de saludar descrita se enmarca en el lugar señalado por cada uno de ellos.

Estas expresiones cumplen un rol central en la interpretación del texto debido a que regulan procesos de movilización del conocimiento que permiten comprender, paso a paso, las relaciones entre las proposiciones presentes en el discurso. Por ejemplo, en el texto anterior, el adverbio de enmarcamiento 'En India' moviliza los conocimientos previos que el lector tiene sobre este país, para hacerlo capaz de evaluar si lo que propone el adverbio para las oraciones posteriores puede ser admitido como verdaderamente propio de la India (esto mismo ocurrirá, de forma sucesiva en el ejemplo, con el resto de los países mencionados). En otros términos, la expresión introductoria ejercida por el adverbio será determinante para evaluar las condiciones de veracidad o falsedad de las oraciones que enmarca.

La segunda función que cumplen los adverbios de enmarcamiento es organizar el discurso, distribuyendo su contenido proposicional en bloques (Charolles, 2005; Charolles et al., 2005). Efectivamente, estos adverbios suelen ser utilizados en serie para agrupar los diferentes segmentos del discurso, por lo que cumplen una función de índice. De esta forma, no solo contribuyen con el contenido proposicional de la oración, sino que también asumen funciones organizacionales específicas a nivel de discurso. Por ejemplo, en el siguiente fragmento podemos ver que la información está estructurada en bloques organizados en torno a los adverbios 'en primer lugar', 'en segundo lugar', 'en tercer lugar' y 'en cuarto lugar':

Disponemos de una serie de argumentos que justifican la adopción de una posición favorable a la tutorización del alumnado universitario. En primer lugar, la tutoría ayuda a resolver las dificultades que plantea la mayor heterogeneidad del alumnado, debida a una mayor diversificación del acceso a la Universidad. En segundo lugar, facilita la orientación curricular ligada a las salidas profesionales y al acceso a otros estudios, así como garantiza la transparencia y la comparabilidad exigidas por el Espacio Europeo de Educación Superior. En tercer lugar, contribuye a atender a los estudiantes que tienen dificultad para lograr un seguimiento regular de los estudios. $\mathrm{Y}$ en cuarto lugar, mejora la imagen pública y la proyección externa de la Universidad, así como la fidelización de los estudiantes, y ofrece opiniones que facilitan el aprendizaje a lo largo de la vida (García y Troyano, 2009:1).

Los adverbios de enmarcamiento, entonces, son expresiones de carácter introductorio con respecto al párrafo o segmento textual y tienen como principal fin crear 'universos del discurso', 'espacios mentales' o 'bloques de información'. La dirección que establecen este tipo de expresiones -a diferencia de los conectores y las anáforas- es proyectada hacia adelante, dado que enmarcan un grupo de oraciones que se organizará de forma adyacente a ella, hasta que el 'cuadro' sea cerrado por el autor (Charolles, 1997).

En conclusión, los mecanismos de estructuración del discurso (anáforas, conectores y adverbios de enmarcamiento) cumplen un rol fundamental en la progresión temática. Las anáforas permiten mantener la continuidad temática, ya que establecen y 
actualizan constantemente el tema del texto, mientras que los conectores y adverbios de enmarcamiento, favorecen la progresión semántica. Es decir, explicitan la forma en que la información del texto es renovada, con respecto a la ya existente. Así, los conectores hacen posible vincular los nuevos contenidos proposicionales que aparecen en el discurso con los anteriores; mientras que los adverbios de enmarcamiento, permiten organizar el texto a partir de universos temáticos o bloques de información que agrupan contenidos a partir de un criterio particular. Este criterio proyecta una característica semántica sobre grupos de proposiciones en el texto, explicitando la manera en que el tema progresa, a nivel macro, en el discurso.

\section{Propuesta didáctica: enseñar y evaluar la coherencia en el proceso de producción textual}

A continuación, presentamos una propuesta didáctica diseñada para la enseñanza y el aprendizaje de la coherencia a lo largo del proceso de producción textual. Para esto se plantean tres fases: una inicial en la que se reconoce el fenómeno de la coherencia y se explicita la estrecha relación que existe entre ella y la comprensión del discurso. Una fase intermedia en la que se conceptualiza este fenómeno a partir de la teoría de Charolles, se establecen principios y se describen las transgresiones más comunes a esos principios; y una fase final en la que esos principios se aplican durante las etapas de planificación, textualización y revisión textual.

\subsection{Fase I: acercamiento al fenómeno. Percepciones del lector: coherencia y comprensión lectora}

Dado que la coherencia es el principio mediante el cual el receptor interpreta el discurso, partimos de la base de que el lector, al construir el sentido del texto que lee, es capaz de identificar la intención del mismo y de comprender las razones por las cuales las ideas del texto han sido presentadas en un orden particular. De esta manera, la construcción de la coherencia implica que el lector ponga en marcha operaciones cognitivas de carácter inferencial que le permitan relacionar la información del discurso, con el contexto y sus conocimientos previos, a fin juzgar la coherencia del texto (Charolles, 2011; Colonna et al., 2014).

La propuesta didáctica plantea comenzar por la lectura comprensiva de dos textos (idealmente escritos por estudiantes de años anteriores) cuyos niveles de coherencia sean sustancialmente diferentes. Para esto, se sugiere llevar a cabo una lectura compartida (Solé, 2009) en la que el grupo curso lee el texto y analiza qué tan comprensible o incomprensible es y qué elementos - de manera intuitiva- identifican como causantes de esto.

Esta lectura compartida debe estar centrada en reconstruir la macroestructura del texto (Kintsch, 2004; Van Dijk, 1996), para lo cual se sugiere utilizar las estrategias de comprensión lectora que propone Solé (2009). Con estas estrategias, se busca que los estudiantes sean capaces de determinar (1) si es posible construir el modelo proposicional del texto leído y (2) si es posible identificar la intención del texto. 
Para esta lectura compartida, se aplican los tres momentos de la lectura (Solé, $2009)^{6}$. En el momento de antes de la lectura, se realizan actividades orientadas a establecer hipótesis respecto del propósito y del sentido del texto, a partir de los elementos textuales y paratextuales advertidos por los estudiantes en una revisión inicial del texto.

Durante la lectura, se plantean actividades con el objetivo de que los estudiantes construyan las proposiciones del texto. Para esto ponen especial atención en analizar su coherencia, evaluando si se entiende con facilidad o no. En este punto, el objetivo es detectar-intuitivamente- qué elementos del texto dificultan su comprensión o, en el caso contrario, qué elementos la facilitan. Las observaciones de los alumnos se registran en una parte de la pizarra y, una vez terminada la lectura y el análisis, se sistematizan los comentarios agrupándolos en torno a un criterio relacionado con la coherencia 'comprensión global del texto', 'progresión de las ideas' (ver ejemplo en Tabla 1).

Tabla. 1. Ejemplo de sistematización de comentarios de los alumnos sobre la comprensibilidad de un texto.

\begin{tabular}{|l|l|}
\hline \multirow{5}{*}{ Comprensión global del texto } & - No queda claro cuál es el tema del texto. \\
& - No entiendo cuál es el propósito del texto, qué \\
& - quería lograr el escritor. \\
& - Las ideas no están bien hiladas. \\
& - El pierdo. \\
& quería decir. \\
\hline \multirow{5}{*}{ Progresión de las ideas } & - No sé a qué se refiere esta idea. \\
& - Se desvía continuamente del tema. \\
& - No entiendo qué función cumple esta parte en \\
& - el texto. \\
& - Repite esta idea muchas veces. \\
& - Algunas ideas son incomprensibles. \\
& - Comete errores en el uso de conectores que di- \\
& ficultan la comprensión. \\
\hline
\end{tabular}

Durante este proceso, el docente debe monitorear dos posibles actitudes por parte de los estudiantes: lectores muy cooperativos, que intentan establecer conexiones entre ideas que no existen en el texto (ya sea porque esas relaciones no son explícitas en el texto, o porque no se pueden inferir de manera unívoca) o extremadamente poco cooperativos, es decir, que no realizan inferencias fácilmente realizables.

Por último, después de la lectura, se plantean preguntas orientadas a que los estudiantes, en conjunto, infieran el propósito del texto y su sentido global, para llegar a concluir que, si esto no es posible de hacer, es debido a que los ejemplares analizados tienen problemas de coherencia. En términos concretos, se pretende que los estudiantes comprendan que existe una relación directa entre la coherencia del texto y su

6 Para guiar estos tres momentos, se sugiere ver capítulos 5, 6 y 7 de Solé (2009). 
comprensibilidad: el texto coherente se comprende con mayor fluidez que un texto incoherente y esto, a su vez, se relaciona con la facilidad con que se puede inferir su macroestructura e identificar su propósito.

Además, esta actividad busca que los alumnos tomen conciencia de que es el autor el responsable de construir un texto que facilite al lector la elaboración de sentido y que ellos mismos, cuando asumen el rol de escritor, deben procurar lograr la coherencia. Para favorecer que los estudiantes cumplan con este rol cuando se encuentran en el proceso de producción textual, proponemos, en la fase II, tres principios que se pueden enseñar de manera explícita y sistemática. Estos principios permiten al estudiante adquirir herramientas para elaborar textos coherentes, así como evaluar la coherencia de textos propios y ajenos, sin embargo, no pretenden ser un estudio exhaustivo del fenómeno de la coherencia ni un modelo acabado para el análisis de textos.

\subsection{Fase II: adquisición de conocimiento metacognitivo declarativo y procedimental: operacionalizar la coherencia mediante tres principios y aplicarlos al análisis de textos}

Durante la primera fase de esta propuesta didáctica, los estudiantes tuvieron la oportunidad de acercarse a los textos escritos por sus compañeros y comprender, a grandes rasgos, que la coherencia se relaciona con la capacidad del escritor de explicitar las relaciones entre las ideas del texto de modo que el lector pueda inferir con relativa facilidad su sentido global e intención. Con todo, esta primera aproximación es todavía intuitiva, por lo que resulta fundamental ofrecer a los estudiantes una comprensión más acabada de la coherencia.

Esto implica comprender, por una parte, que la coherencia es el principio mediante el cual interpretamos el discurso y, por otra parte, que la lengua provee de diversos mecanismos mediante los cuales es posible lograrla. Para esto, la segunda fase busca que los estudiantes comprendan qué es la coherencia textual e incorporen ese aprendizaje como parte de sus conocimientos metacognitivos declarativos y procedimentales de escritura (Harris, Santangelo y Graham, 2010), de modo que estén disponibles para ser aplicados durante el proceso de producción textual, en la tercera fase de esta propuesta didáctica.

Adquirir la coherencia como conocimiento metacognitivo declarativo implica que el estudiante (1) identifica y comprende los mecanismos mediante los cuales se estructura el discurso y (2) es capaz de utilizarlos para producir un texto cuya intención y sentido global, pueden ser inferidos por otros.

Desde esta óptica, la lectura compartida y el análisis de los textos realizados en la primera fase son una estrategia de activación de conocimientos previos, que favorece la adquisición de nuevos conocimientos especializados. La presente propuesta didáctica propone enseñar estos conocimientos en torno a tres principios fundamentados en la teoría de Charolles y sus colaboradores ${ }^{7}$, lo cuales se describen a continuación:

Estos principios toman como punto de partida cuatro meta-reglas (Charolles, 1978] propuestas por el autor en un artículo que busca contribuir a resolver a los problemas que enfrentan los profesores en la enseñanza y la evaluación de la coherencia. Estas meta-reglas son: Meta-regla de repetición: para que un texto sea coherente debe contener en su desarrollo lineal, elementos de recurrencia estricta. Para asegurar la existencia de tales repeticiones, la lengua cuenta con recursos como: pronombres, definiciones, sustitución léxica, referencias deícticas contextuales, entre otras. Meta-regla de progresión: para que un texto sea coherente su desarrollo debe 
i. Congruencia entre las ideas.

Para que un texto sea coherente, las ideas expuestas en él deben ser congruentes entre sí y congruentes con el universo del discurso en el que están insertas. Esto implica que:

1. Ninguna idea debe contradecir el significado de otra anteriormente expuesta - o susceptible de ser inferida a partir de un contenido anterior-.

2. Todas las ideas del texto deben ser congruentes con el universo del discurso en el que están insertas. Por ejemplo, la oración: En Finlandia, los sectores socioeconómicamente desfavorecidos acceden a una educación de calidad. Resulta congruente con el universo del discurso que evoca el adverbio de enmarcamiento 'En Finlandia'. Sin embargo, si reemplazamos 'En Finlandia' por 'En Chile' la proposición resultaría incongruente con el marco que evoca.

ii. Progresión temática.

Para que un texto sea coherente todas sus ideas deben estar conectadas entre sí. Esto implica tener una adecuada progresión del tema que asegure que cada proposición contenga un elemento que se repita y otro que aporte información nueva. El elemento que se repite corresponde a 'lo dado' y la información nueva, valga la redundancia, a 'lo nuevo'. Esta estructura controla la progresión de los temas a lo largo del texto escrito y provee al lector de un punto focal consistente, que le ayuda a interpretar cada parte del discurso en relación con las demás (Weissberg, 1984; Van Dijk, 1996].

En otras palabras, cada proposición debe referir a una idea anterior y aportar información nueva que justifique su presencia en el texto. En el fragmento que se expone a continuación puede observarse cómo a través del uso de referencias y la renovación permanente de la información, se mantiene el equilibrio entre lo dado y lo nuevo.

En el corazón de Karnak se encuentra el templo de Amón, dedicado al rey de los dioses. Con sus interminables patios, salas y colosos y un enorme lago sagrado, su escala y complejidad resultan abrumadoras. Desde sus modestos comienzos en la dinastía XI, un faraón tras otro fueron añadiendo construcciones o transformando las existentes con el fin de dejar su sello en el templo más importante del país ${ }^{8}$ (Barragán, 2008:188].

En el ejemplo anterior, la primera proposición introduce en el absoluto 'templo de Amón', que se constituye a lo largo del texto en 'lo dado'. Las repeticiones: 'sus', 'su', 'sus' y 'templo más importante del país' mantienen el referente a lo largo del párrafo, gracias a lo cual no existen pérdidas de referente. Por otra parte, estas repeticiones favorecen la introducción permanente de nuevas informaciones sobre

acompañarse de un aporte semántico constantemente renovado. Esta meta-regla indica que el texto no puede contentarse con repetir una información ya dicha, sino que debe, además, debe aportar constantemente informaciones nuevas. Meta regla de no contradicción: para que un texto sea coherente no debe introducirse en su desarrollo ningún elemento que contradiga semánticamente un contenido anteriormente expuesto, o susceptible de ser inferido a partir de un contenido anterior. Meta regla de relación: para que un texto sea coherente los hechos que en él se exponen deben estar relacionados al mundo representado del que forman parte. Esta regla es de naturaleza pragmática, ya que reposa únicamente sobre la percepción de una relación de congruencia entre la acción expuesta por las secuencias textuales y el universo representado creado por el discurso (Charolles, 1978].

8 Resaltado propio. 
el templo de Amón: su ubicación en el corazón de Karnak, que posee patios, salas, colosos y un enorme lago, y las características de su fachada.

iii. Relación entre las ideas.

Para que un texto sea coherente, todas las ideas deben estar relacionadas entre sí y deben estar organizadas de acuerdo con un orden lógico congruente con la intención comunicativa del texto. Los mecanismos para relacionar la información, que permiten al lector construir el sentido global del texto sin dificultad, pueden ser:

1. Adyacencia: la relación entre las ideas se infiere por la yuxtaposición.

2. Adverbios de enmarcamiento: relacionan las ideas entre sí y las organizan en torno a criterios definidos.

3. Conectores: explicitan las relaciones que existen entre las ideas del texto.

Una vez presentados los tres principios de la coherencia, se vuelve a los textos leídos en la fase anterior con el objetivo de aplicar dichos conocimientos a su análisis. Lo anterior supone volver a leer los textos e intentar determinar la causa de los problemas identificados en la fase anterior. A continuación, presentamos una posible clasificación y descripción de los principales problemas de coherencia que pueden presentarse en un texto, considerando los tres principios enunciados:

Tabla 2. Principios de la coherencia y transgresiones más comunes

\begin{tabular}{|l|l|}
\hline Principio de coherencia & Transgresiones más comunes \\
\hline \multirow{5}{*}{ Congruencia entre las ideas } & $\begin{array}{l}\text { Contradicción: una idea del texto contraría el significado } \\
\text { de otra expuesta anteriormente, por ejemplo, en el siguiente } \\
\text { texto se plantean dos ideas que no pueden ser ciertas al mis- } \\
\text { mo tiempo: Francisco es vegetariano así que come carne } \\
\text { solo de vez en cuando. }\end{array}$ \\
\cline { 2 - 3 } Progresión temática & $\begin{array}{l}\text { Incongruencia: una idea del texto no es congruente con el } \\
\text { universo creado por el discurso. En el ejemplo, el texto pre- } \\
\text { senta una proposición que no es congruente con el universo } \\
\text { 'En Santiago': En Santiago, los niveles de contaminación } \\
\text { son casi imperceptibles. }\end{array}$ \\
\hline & $\begin{array}{l}\text { Pérdida de referente: la referencia de alguna idea del texto } \\
\text { no está unívocamente establecida. En el ejemplo siguiente } \\
\text { no se sabe con certeza a qué refiere la expresión 'esta for- } \\
\text { ma': No creo que exista una carrera adecuada para cada } \\
\text { género, salvo algunas excepciones como ser matrona o gi- } \\
\text { necólogo, porque creo que es más cómodo para una mujer } \\
\text { ser tratada de esta forma. }\end{array}$ \\
\cline { 2 - 3 } & $\begin{array}{l}\text { Cambio de tema abrupto: sucede cuando se inserta un tema } \\
\text { nuevo que no contiene información dada ni estántimamente } \\
\text { relacionada con una idea expuesta anteriormente en el texto. }\end{array}$ \\
\cline { 2 - 3 } & $\begin{array}{l}\text { Redundancia: una oración o un conjunto de oraciones solo } \\
\text { contiene proposiciones ya dichas en el texto, por lo tanto, } \\
\text { su presencia no tiene justificación ya que no contribuyen en } \\
\text { nada al logro de su propósito. }\end{array}$ \\
\hline
\end{tabular}




\begin{tabular}{|l|l|}
\hline Secuenciación azarosa de ideas: un segmento del texto no \\
se entiende ya que el orden en que las ideas están presen- \\
tadas parece fortuito. Esto implica que al lector no le es \\
posible inferir qué intención explica que las ideas hayan \\
sido secuenciadas del modo en que lo están. En otras pa- \\
labras, no se sabe por qué razón una idea ha sido puesta al \\
lado de la otra: \\
Fuera de estos casos, en teoría son completamente unisex. \\
Tanto hombres como mujeres tienen la capacidad para \\
cumplirlos a cabalidad, es completamente personal, saben \\
cuál es la habilidad dominante en eso y si se desea seguir \\
ese camino.
\end{tabular}

La propuesta consiste, entonces, en que los estudiantes en conjunto discutan los problemas de coherencia detectados anteriormente y los relacionen con estas transgresiones de modo que puedan contar con categorías, a partir de las cuales puedan llegar a acuerdos sobre la coherencia de textos propios y escritos por otros.

\subsection{Fase III: monitorear y autorregular la coherencia a lo largo del proceso de producción textual}

Una vez realizada la fase I y II, el estudiante tendrá una mayor conciencia respecto de que el proceso de escritura requiere que el autor prepare el texto para ser leído por otros. Lo anterior requiere utilizar adecuadamente mecanismos de estructuración del discurso - anáforas, conectores y adverbios de enmarcamiento - para ofrecer al lector señales interpretativas que le permitan construir el sentido del discurso.

Proponemos que este conocimiento metacognitivo sea incorporado en el proceso mismo de producción textual, que, de acuerdo con el modelo de Didactext (2015), consta de cinco etapas: Acceso al conocimiento, cuyas estrategias cognitivas y metacognitivas están orientadas a la adquisición de información (leer para escribir) y a la reflexión sobre el proceso de escritura. Planificación, cuyas estrategias tienen como objetivo que el escritor seleccione, jerarquice y organice la información del texto que va a escribir. Redacción, que plantea estrategias para desarrollar el texto de acuerdo al plan tomando en cuenta la audiencia, el propósito del texto y la estructura del 
género discursivo. Revisión, cuyo objetivo es identificar problemas en la producción textual y resolverlos de modo que se ajuste correctamente a la intención, la audiencia y el tema. Edición, que consiste en preparar el texto para difundirlo a su audiencia, adecuando su diseño y presentación al medio en el que será publicado. Presentación oral, en la que se exponen las ideas principales, con ayuda de soporte audiovisual, utilizando un lenguaje formal conforme al contexto académico.

La intención de la propuesta didáctica que se plantea a continuación es intervenir el desarrollo de tres de estas fases descritas por el modelo de Didactext: planificación, escritura y revisión, dado que son clave para la construcción de la coherencia. Consideremos, por ejemplo, que el docente propone a sus estudiantes una tarea de escritura consistente en la elaboración de un ensayo literario. Dicha tarea debería llevarse a cabo a lo largo de un proceso de enseñanza aprendizaje de la producción textual que contemple todas las etapas del modelo descrito (acceso al conocimiento, planificación, redacción, revisión, edición y presentación oral). A través de este proceso, se enseña a los estudiantes a aplicar las estrategias cognitivas y metacognitivas - propuestas por el modelo- para que puedan escribir un texto que cumpla las demandas del género, el tema y la audiencia (Didactext, 2015).

Se propone, entonces, que el docente incorpore en la etapa de planificación las actividades que se plantean en la sección 3.3.1 y que tienen como objetivo proyectar la coherencia. En la fase de redacción, incorporar las actividades propuestas en la sección 3.3.2 para ayudar al estudiante a monitorear y autorregular la construcción de la coherencia. Por último, que incorpore en la fase de revisión las actividades planteadas en la sección 3.3.3, que buscan evaluar el logro de la coherencia, identificar errores y realizar mejoras en el texto.

\subsubsection{Etapa de planificación: proyectar la construcción de la coherencia}

En esta fase se propone una estrategia didáctica que consiste en elaborar un plan de escritura en el que se determine el propósito general del texto (de acuerdo al género discursivo) y se proyecte su sentido global. Además, este plan de escritura contempla explicitar, en términos muy generales, la secuencia en la que las ideas serán transmitidas y reflexionar en qué grado esas ideas, en ese orden, contribuyen al logro del propósito del texto. De este modo, la construcción del sentido del texto estará estrechamente relacionada con la estructuración de la totalidad del discurso a partir de las características relativamente estables de género.

Para esto la Figura 1 propone un organizador gráfico en el que se escribe el propósito del texto y se proyecta su sentido global. Luego, se delinea la secuenciación de las ideas del texto y se justifica su presencia en el texto, en la columna contigua. Las flechas indican que la 'Organización de las ideas' debe ser congruente con el significado global que se pretende transmitir mediante el texto y que la 'Función de las ideas' debe contribuir a lograr la intención comunicativa del texto. 


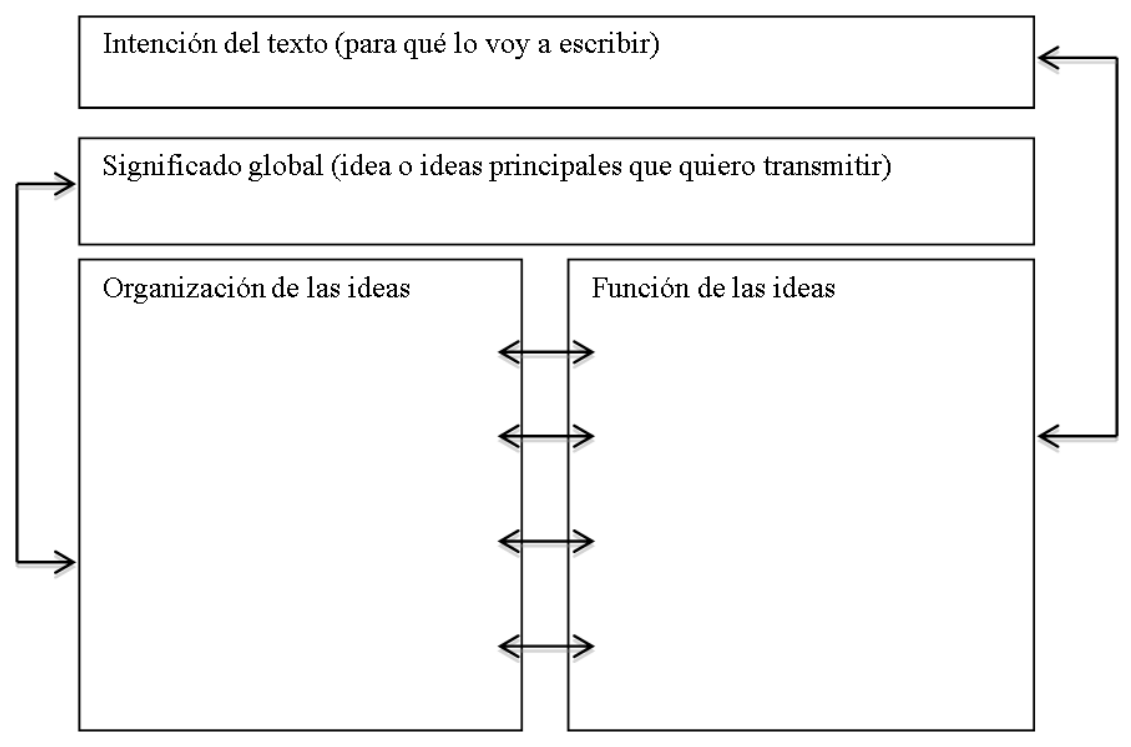

Figura 1. Planificar proyectando la coherencia del texto.

\subsubsection{Etapa de textualización: monitorear y autorregular la construcción de la coherencia}

Durante la textualización se orquestan diversos procesos y subprocesos orientados a convertir el plan de escritura en un discurso plenamente desarrollado. Para esto, el escritor textualiza las ideas consignadas en el organizador gráfico y las elabora teniendo en cuenta que debe cuidar el cumplimiento de los tres principios:

1. Congruencia entre las ideas.

2. Progresión temática.

3. Relación entre las ideas.

Para favorecer este monitoreo, se sugiere que el profesor detenga el proceso de textualización y solicite a sus estudiantes leer lo que han escrito y compararlo con el plan de escritura. Si existen diferencias entre el plan y el texto escrito hasta el momento, el estudiante debe decidir si cambiar el plan de escritura o cambiar lo que ha escrito hasta el momento, con el objetivo de conseguir un texto más coherente y que consiga lograr con su propósito comunicativo.

\subsubsection{Etapa de revisión: evaluar el logro de la coherencia, identificar errores y realizar mejoras}

Durante la revisión se pide a los estudiantes que intercambien su primer borrador para evaluar el logro de la coherencia. Para esto, cada estudiante lee el texto del compañero y detecta posibles transgresiones a los principios de la coherencia (ver Tabla 2). Una vez hecho esto, el revisor escribe al autor del texto un comentario que 
refiere al nivel de logro que, según ellos, alcanza el texto respecto de los principios de la coherencia. Luego, se intercambian las correcciones y, en base a ellas, el autor comienza la reescritura del texto.

Resulta importante aclarar que proponemos una revisión acotada al ámbito de la coherencia y que hay otros criterios que se deben incluir como: corrección de errores orto-tipográficos, errores gramaticales, errores de hecho y transgresiones de esquemas, errores de estructura del texto, complejidad o tono inadecuados, entre otros.

\section{Conclusiones}

Consideramos que el trabajo de Michel Charolles y sus colaboradores resulta de gran utilidad para la didáctica de la escritura, en vista de que aborda la coherencia desde un enfoque procedimental, es decir, a partir de los problemas de coherencia percibidos por hablantes y oyentes en condiciones naturales del discurso.

A nuestro juicio, la utilidad de esta propuesta radica en que permite incorporar la enseñanza de la coherencia dentro del proceso de producción textual y comprenderla como una característica constitutiva del discurso, sin la cual un texto no puede lograr su propósito comunicativo. De este modo, los principios que se proponen 'congruencia entre las ideas', 'progresión temática' y 'relación entre las ideas' no tienen la intención de abordar ni explicar la coherencia en toda su complejidad, sino que más bien, operacionalizar algunos de sus elementos fundamentales -según la teoría de Charolles- lo cual permite al estudiante aplicar este conocimiento en las actividades de monitoreo y autorregulación de la producción textual.

En esta misma línea, las transgresiones a los principios de la coherencia 'contradicción', 'incongruencia', 'pérdida de referente', 'redundancia', 'secuenciación azarosa de ideas al interior del párrafo', 'desorganización general del texto', 'conector inadecuado' no pretenden clasificar exhaustivamente los problemas de coherencia, sino que más bien, agrupar los problemas más recurrentes en categorías reducidas -y, por lo tanto, más manejables- que permitan identificar y diagnosticar problemas; así como orientar posibles mejoras en los textos.

\section{Referencias bibliográficas}

Agencia de la Calidad de la Educación (2014): Síntesis resultados de aprendizaje. Simce Escritura 2014 [en línea]. http://archivos.agenciaeducacion.cl/resultados-2014/Sintesis_ Resultados_6B_Escritura_2014.pdf [consultado el 20 de junio de 2016]

Bajtín, Mijail (2008): Estética de la creación verbal, trad. T. Bubnova, Buenos Aires, Siglo XXI; obra original publicada en 1979.

Balgopal, Meena y Allison Wallace (2013): "Writing-to-learn, writing-to-communicate, \& scientific literacy", The american biology Teacher, 75.3, 170-175.

Barragán, Charles (Coord.) (2008): Guías Visuales. Egipto, Madrid, El País-Aguilar.

Bazerman, Charles (2012a): "Genre as social action", en J. P. Gee y M. Handford (Eds.), The Routledge handbook of discourse analysis, New York, Routledge, 226-238.

Bazerman, Charles (2012b): "Writing, cognition and affect from the perspectives of sociocultural and historical studies of writing”, en V. Wise (Ed.), Past, present and future con- 
tributions of cognitive writing research to cognitive psychology, New York, Psychology Press, 89-104.

Bereiter, Carl, y Marlene Scardamalia (1987): The Psychology of Written Composition. New Jersey, Lawrence Erlbaum Associates.

Bitrán, Marcela; Denesse Zúñiga, Paulina Flotts, Oslando Padilla y Rodrigo Moreno, (2009): "Mejoría en las habilidades de comunicación escrita de estudiantes de medicina: Impacto de un taller de escritura", Revista médica de Chile, 137.5, 617-624.

Cabrera, Marcela (2014): "El instrumento CODICE-Derecho y su aplicación en la Facultad de Derecho de la Universidad de Chile", Revista pedagogía universitaria y didáctica del derecho, 1.1, 2-19.

Charolles, Michel (2011): "Cohérence et cohésion du discours", en Dimensionen der Analyse Texten und Diskursivent-Dimensioni dell'analisi di testi e discoursi, Berlín, Lit, 153-173.

Charolles, Michel (2005): "Framing adverbials and their role in discourse cohesion, from connection to forward labelling", presentado en el Symposium on the Exploration and Modelling of Meaning, Biarritz, Francia.

Charolles, Michel (1997) : "L'encadrement du discours", Monographie. Cahier de Recherche Linguistique, 6, 1-73.

Charolles, Michel (1995): “Cohésion, cohérence et pertinence du discours”, Travaux de linguistique, 29.112, 125-151.

Charolles, Michel (1989): “Text coherence and text interpretation processing”,en M. E. Conte, J. S. Petöfi y E. Sözer (Eds.), Text and discourse connectedness: proceedings of the Conference on Conexity and Coherence, Urbino, July, 16-21, 1884, Amsterdam, John Benjamin B.V., 377-386.

Charolles, Michel (1983): "Coherence as a principle in the interpretation of discourse", Text. Interdisciplinary Journal for the Study of Discourse, 3.1, 71-98.

Charolles, Michel (1978): "Introduction aux problemes de la coherence des textes: Approche théorique et étude des pratiques pédagogiques", Langue française, 38, 7-41.

Charolles, Michel, y Denis Vigier (2005): "Les adverbiaux en position préverbale: portée cadrative et organisation des discours", Langue française, 4, 9-30.

Charolles, Michel, Anne Le Draoulec, Marie Paul Péry-Woodley y Lourdes Sarda (2005): "Temporal and spatial dimensions of discourse organisation", Journal of French Language Studies, 15.2, 115-130.

Colonna, Saveria, Michel Charolles, Lourdes Sarda, y Joel Pynte (2014) : "Effect on Comprehension of Preposed versus Postposed Adverbial Phrases", Journal of psycholinguistic research, 43.6, 771-790.

Concha, Soledad, y Jeanne Paratore (2011): "Local coherence in persuasive writing: An exploration of Chilean students' metalinguistic knowledge, writing process, and writing products", Written Communication, 28.1, 34-69.

Concha, Soledad, Soledad Aravena, Carmen J. Coloma y Verónica Romero (2010): "Escritura expositiva en tres niveles de escolaridad: coherencia y dominio de recursos lingüísticos", Literatura y lingüística, 21, 75-92.

Didactext (2015): "Nuevo marco para la producción de textos académicos”, Didáctica. Lengua y Literatura, 27, 219-254.

Errázuriz, María Constanza, Lucía Arriagada, Maritza Contreras y Carla López (2015): "Diagnóstico de la escritura de un ensayo de alumnos novatos de Pedagogía en el campus Villarica UC, Chile", Perfiles educativos, 37.150, 76-90.

García, Alfonso, y Yolanda Troyano (2009): "El Espacio Europeo de Educación Superior y la figura del profesor tutor en la Universidad”, Red-U. Revista de Docencia Universitaria, 3, 1-10. 
Halliday, Michael, y Ruqaiya Hasan (1976): Cohesion in English. Essex, Longman.

Harris, Karen, Tania Santangelo y Steve Graham (2010): "Metacognition and strategies instruction in writing”, en H. Salatas y W. Schneider (Eds.), Metacognition, strategy use, and instruction, Nueva York, The Gilford Press, 226-256.

Kintsch, Walter (2004): "The Construction-Integration model of text comprehension and its implications for instruction", en R. Ruddell y N. Unrau (Eds.), Theoretical Models and Processes of Reading, Michigan, University of Michigan-International Reading Association, 1270-1328.

Klein, Perry, y Mary Rose (2010): “Teaching argument and explanation to prepare junior students for writing to learn", Reading Research Quarterly, 45.4, 433-461.

Sarda, Laure, Shirley Carter-Thomas, Benjamin Fagard y Michel Charolles (2014): "Text structuring devices: an overview", Pragmatic Approaches to Text Structuring, California, UCL Editions, 1-50.

Scardamalia, Marlene, y Carl Bereiter (1992): "Dos modelos explicativos de los procesos de composición escrita", Infancia y aprendizaje, 15.58, 43-64.

Solé, Isabel (2009): Estrategias de comprensión lectora, Barcelona Graó.

Sotomayor, Carmen, Graciela Lucchini, Percy Bedwell, Manuela Biedma, Carolina Hernández y Daniela Molina (2013): "Producción escrita en la Educación Básica: análisis de narraciones de alumnos de escuelas municipales de Chile", Onomázein, 27, 53-77.

Van Dijk, Teun A. (1996): La ciencia del texto. Barcelona, Paidós.

Weissberg, R. C. (1984): “Given and new: Paragraph development models from scientific English”, Tesol Quarterly, 18.3, 485-500. 